\title{
Tissue Factor Regulation by miR-520g in Primitive Neuronal Brain Tumor Cells
}

\section{A Possible Link between Oncomirs and the Vascular Tumor Microenvironment}

\author{
Esterina D’Asti, ${ }^{*}$ Annie Huang, ${ }^{\dagger}$ Marcel Kool, ${ }^{\ddagger}$ Brian Meehan, ${ }^{*}$ Jennifer A. Chan, ${ }^{\S}$ Nada Jabado, ${ }^{*}$ Andrey Korshunov, ${ }^{\top} \|$ \\ Stefan M. Pfister, ${ }^{\ddagger * *}$ and Janusz Rak* \\ From the Research Institute of the McGill University Health Centre, * Montreal Children's Hospital, McGill University, Montreal, Quebec, Canada; the Division of \\ Hematology-Oncology, ${ }^{\dagger}$ Hospital for Sick Children, Toronto, Ontario, Canada; the Division of Pediatric Neurooncology ${ }^{\ddagger}$ and the Clinical Cooperation Unit \\ Neuropathology, "German Cancer Research Center, Heidelberg, Germany; the Department of Pathology, ${ }^{\S}$ Cumming School of Medicine, University of Calgary, \\ Calgary, Alberta, Canada; and the Departments of Neuropathology" and Pediatric Hematology and Oncology, ** Heidelberg University Hospital, Heidelberg, Germany
}

\author{
Accepted for publication \\ October 21, 2015. \\ Address correspondence to \\ Janusz Rak, M.D., Ph.D., \\ Montreal Children's Hospital \\ Research Institute, McGill Uni- \\ versity, 4060 St Catherine W, \\ Montreal, QC, Canada H3Z \\ 2Z3. E-mail: janusz.rak@ \\ mcgill.ca.
}

\begin{abstract}
Pediatric embryonal brain tumors with multilayered rosettes demonstrate a unique oncogenic amplification of the chromosome 19 miRNA cluster, C19MC. Because oncogenic lesions often cause deregulation of vascular effectors, including procoagulant tissue factor (TF), this study explores whether there is a link between C19MC oncogenic miRNAs (oncomirs) and the coagulant properties of cancer cells, a question previously not studied. In a pediatric embryonal brain tumor tissue microarray, we observed an association between C19MC amplification and reduced fibrin content and TF expression, indicative of reduced procoagulant activity. In medulloblastoma cell lines (DAOY and UW228) engineered to express miR-520g, a biologically active constituent of the C19MC cluster, we observed reduced TF expression, procoagulant and TF signaling activities (responses to factor VIIa stimulation), and diminished TF emission as cargo of extracellular vesicles. Antimir and luciferase reporter assays revealed a specific and direct effect of miR-520g on the TF $3^{\prime}$ untranslated region. Although the endogenous MIR520G locus is methylated in differentiated cells, exposure of DAOY cells to 5-aza- $2^{\prime}$ deoxycytidine or their growth as stem cell-like spheres up-regulated endogenous miR-520g with a coincident reduction in TF expression. We propose that the properties of tumors harboring oncomirs may include unique alterations of the vascular microenvironment, including deregulation of TF, with a possible impact on the biology, therapy, and hemostatic adverse effects of both disease progression and treatment. (Am J Pathol 2016, 186: 446-459; http://dx.doi.org/10.1016/j.ajpath.2015.10.020)
\end{abstract}

We have previously postulated that the molecular heterogeneity of brain tumors may engender diversity in their vascular properties, including activation of distinct, subtype-specific angiogenic and coagulant effectors downstream of the respective mutations in oncogenes or tumor suppressors. ${ }^{1}$ Although oncogenic lesions in protein-coding genes have been the focus of related prior studies, embryonal tumors with multilayered rosettes (ETMRs) represent a distinct paradigm because of the preponderance of changes affecting oncomirs. The vascular consequences of this mode of transformation remain unknown.
ETMRs are highly aggressive tumors of neuronal origin. The disease occurs in infants and is incurable, with an average overall survival of approximately 1 year after diagnosis. ${ }^{2}$ Histologically, ETMRs present with significant vascular anomalies,

\footnotetext{
Supported by Canadian Institutes of Health Research foundation grants MOP 102736 and MOP 111119 (J.R.), Cancer Research Society (J.R.), the Jack Cole Chair in Pediatric Hematology/Oncology (J.R.), the CIBC Bike Challenge Studentship (E.D.), and Fonds de Recherche du Québec - Santé (Québec Research Fund - Health) (E.D.).

Disclosures: None declared.
} 
including endothelial hyperplasia, glomeruloid vessel formation, hemorrhage, and necrosis. ${ }^{3,4}$ More than $90 \%$ of these tumors harbor a unique genomic amplification of a miRNA cluster on chromosome 19 (C19MC), which is regarded as a driver event in this setting. ${ }^{2,5-8}$ The postulated oncogenic role of several miRNAs comprising the C19MC cluster has been most extensively studied for miR-517c and miR-520g ${ }^{6}$ and linked to intrinsic cellular changes, although the vascular targets of these putative oncomirs have not been fully established.

miRNAs are short RNA sequences (approximately 23 nucleotides) that target mRNA transcripts for degradation or inhibit their translation mostly via binding to specific sites within the $3^{\prime}$ untranslated region (UTR). ${ }^{9}$ This mechanism may exert an oncogenic effect mostly through negative regulation of tumor-suppressing pathways involved in the control of cellular growth and survival. ${ }^{10}$ However, it is increasingly clear that miRNA networks also contribute to the regulation of the tumor vascular microenvironment by controlling angiogenesis. ${ }^{11,12}$

Relatively little is known about the role of miRNA networks in other vascular processes, such as hemostatic anomalies and coagulopathy, often triggered by the progression and therapy of human malignancies. ${ }^{13}$ More important, activation of the coagulation system has been implicated in the onset of inflammation, angiogenesis, metastasis, invasion, and cessation of tumor dormancy in various tumor contexts. ${ }^{1,14}$ In this regard, the core regulatory events are often initiated by binding of the blood-borne coagulation factor VII/VIIa (FVIIa) to its cellular receptor, tissue factor (TF), which is a transmembrane protein related to the cytokine type II receptor family. ${ }^{15} \mathrm{TF}$ is endowed with important vascular functions because of the combination of clotting and signaling activities. ${ }^{16}$ Assembly of the TF/FVIIa complex activates the coagulation cascade by generating active factor $\mathrm{Xa}$ and thrombin (IIa), a process resulting in the pericellular formation of a fibrin clot and platelet activation. ${ }^{15,17}$ At the same time, coagulation complexes and intermediates (TF/factors $\mathrm{VII} / \mathrm{Xa} / \mathrm{IIa}$ ) present on the cell surface trigger intracellular signals through enzymatic activation of G-protein-coupled protease activated receptors, especially 1 and 2 . These events normally contribute to the expression of genes involved in the cellular wound healing program, including plasminogen activator inhibitor 1 (PAI-1), IL-8, vascular endothelial growth factor, and several others. ${ }^{18}$ In cancer, these responses may modulate the vascular microenvironment encompassing both angiogenesis and inflammation, as well as contribute to cancer invasiveness and disease progression. ${ }^{19}$

Although cancer-related, spontaneous, iatrogenic, or subclinical perturbations of the coagulation system (local and systemic) are often regarded as non-specific, growing evidence suggests the contrary. For example, both the expression and emission of TF as extracellular vesicles (EVs) are up-regulated by several oncogenic pathways [rat sarcoma (RAS), epidermal growth factor receptor (EGFR), hepatocyte growth factor receptor (MET)], some of which may also influence other elements of the cancer coagulome. ${ }^{16,20-22}$ Profiles of coagulation-related genes segregate with molecular subtypes of primary brain tumors, such as glioblastoma multiforme ${ }^{23}$ and medulloblastoma (MB). ${ }^{1}$ Furthermore, tumor types differ markedly in their ability to provoke thrombotic complications. ${ }^{24,25}$ In this context, the effects of oncomirs associated with distinct types of brain tumors remain largely unstudied.

Herein, we document the negative regulatory effects of the putative oncomir, miR-520g, on the expression of TF in embryonal brain tumor cells. We observed that TF expression is reduced in association with C19MC amplification, a genetic lesion unique to ETMR. Lower levels of TF corresponded with decreased fibrin content, a marker of clotting activation. Among the C19MC miRNAs that are upregulated in ETMR, miR-520g exhibits the strongest potential for targeting the TF $3^{\prime} \mathrm{UTR}$, and can specifically and directly suppress the cellular expression and EVmediated release of $\mathrm{TF}$ in vitro. miR-520g-expressing cells also exhibit reduced procoagulant activity and signaling responses to coagulation factor stimulation. Endogenous expression of miR-520g by cells grown as tumor spheres leads to concomitant TF down-regulation, suggesting a link between a stem-like state and regulation of the coagulation pathway. These observations point to a unique and important role of oncomir networks in defining the vascular properties of embryonal brain tumors and suggest consideration of these effects in personalized cancer treatment.

\section{Materials and Methods}

\section{Reagents}

Human FVIIa and factor X (FX) were obtained from Sekisui Diagnostics (Stamford, CT). 5-Aza-2'-deoxycytidine was purchased from Sigma (Oakville, ON, Canada). All plasmid transfections were performed using lipofectamine 2000 (Life Technologies, Burlington, ON, Canada). The human-specific TF 4503 (Sekisui Diagnostics), human-specific glyceraldehyde-3-phosphate dehydrogenase (Abcam, Toronto, ON, Canada), and $\beta$-actin (Sigma) primary antibodies were used for Western blot detection.

\section{Cell Culture and Treatments}

Embryonal brain tumor (MB) cell lines, including DAOY (Dr. Nada Jabado, McGill University, Montreal, QC, Canada), DAOY and UW228 control (-pCDH), and miR-520g-overexpressing $(-520 \mathrm{~g})$ stable transfectants, and mouse endothelioma (EOMA) cells were described earlier. ${ }^{6,26}$ These cells were maintained in $\boldsymbol{\alpha}$-minimal essential medium (Wisent, St-Bruno, QC, Canada) and Dulbecco's modified Eagle's minimal essential medium (Wisent), respectively, supplemented with $1 \%$ penicillin/streptomycin (pen/strep; Life Technologies) and 10\% fetal bovine serum (FBS; Wisent). U373vIII adult glioblastoma multiforme cells 
expressing the EGFRvIII oncogene (Dr. Abhijit Guha, University of Toronto, Toronto, ON, Canada) ${ }^{16}$ were cultured in Dulbecco's modified Eagle's minimal essential medium (Wisent) supplemented with $1 \%$ pen/strep and $10 \%$ FBS. The ETMR cell line BT183 was derived and maintained as previously described. ${ }^{27}$ As specified, the cells were treated with $50 \mathrm{ng} / \mathrm{mL}$ hepatocyte growth factor, $100 \mathrm{ng} / \mathrm{mL}$ fibroblast growth factor $2,10 \mathrm{ng} / \mathrm{mL}$ platelet-derived growth factor BB (Sigma), or $50 \mathrm{ng} / \mathrm{mL}$ transforming growth factor- $\alpha$, which were purchased from Life Technologies, unless otherwise indicated. For sphere formation experiments, DAOY cells were grown in stem cell media, as previously described, ${ }^{28}$ whereas monolayer cultures were grown in $10 \%$ FBS. For DNA demethylation, DAOY and U373vIII cells were seeded in $10-\mathrm{cm}$ petri dishes. The following day, cells were incubated with $5 \mu \mathrm{mol} / \mathrm{L}$ 5-aza-2'-deoxycytidine and treated for 3 days before Trizol extraction of RNA. ${ }^{29}$

\section{Histology/Immunohistochemistry}

The embryonal brain tumor tissue microarrays were generated at the German Cancer Research Center (Heidelberg, Germany). Tumor samples were characterized as LIN28/ C19MC negative (ie, non-ETMRs) or INI1 positive (ie, nonatypical teratoid/rhabdoid tumors). After staining procedures, all slides were scanned at $\times 40$ magnification using ScanScope (Goodman Cancer Research Institute, McGill University), and viewed on Aperio ImageScope software version 11.2.0.780 (Leica Microsystems Inc., Concord, ON, Canada). After rehydration of the tissue, antigen retrieval was performed using Antigen Unmasking Solution (Vector Labs, Burlington, ON, Canada) for 20 minutes at $98^{\circ} \mathrm{C}$. The slide was allowed to cool for 30 minutes before washing and blocking for 2 hours with $10 \%$ rabbit serum. The slide was incubated at $4^{\circ} \mathrm{C}$ overnight with 1:10,000 sheep anti-human TF primary antibody (Affinity Biologicals, Ancaster, ON, Canada). The slide was washed and then blocked for endogenous peroxidase activity for 1 hour at $4{ }^{\circ} \mathrm{C}$ in a $1.5 \%$ $\mathrm{H}_{2} \mathrm{O}_{2}$ solution. The Vectastain Elite kit (Vector Labs) for sheep IgG antibody detection was used, according to the manufacturer's instructions, for incubation with the biotinylated secondary antibody and $\mathrm{ABC}$ reagent. ImPACT 3,3'-diaminobenzidine peroxidase substrate (Vector Labs) was used to detect biotinylation before counterstaining with hematoxylin or methyl green. TF-positive staining was calculated as percentage area stained multiplied by the average staining intensity, as evaluated by four independent blinded observers (including E.D. and J.R.). The percentage area was measured using ImageJ software version $1.47 \mathrm{a}$ (NIH, Bethesda, MD; http://imagej.nih.gov/ij), and the staining intensity was assessed on the arbitrary scale of 1 to 4 . Martius scarlet blue staining for fibrin was performed at the Goodman Cancer Research Center Histology Core (McGill University) as per standard protocol, and scored (0 to 3) by a staff pathologist (blinded) on the basis of the number and area of positive foci: 0 indicates no significant amount; 1 , very few small foci (0 to 4); 2, mild amounts, few small foci (5 to 10), and/or very few mildly extensive areas; and 3 , moderate amounts, numerous small foci, and/or few more extensive areas. All other microscope images were captured using a Zeiss Axiophot microscope and associated AxioVision SE64 Rel. 4.8 software version 15.0 (Zeiss, Toronto, ON, Canada) at $\times 40$ or $\times 10$ magnification.

\section{Expression Analysis of mRNA in Patient Samples}

Gene expression data, generated with Affymetrix U133 Plus 2.0 arrays (Affymetrix Inc., Santa Clara, CA), were accessed from public sources deposited in Gene Expression Omnibus (http://www.ncbi.nlm.nih.gov/geo; accession numbers GSE49243, GSE10327, GSE37418, and GSE12992), or have been generated at the German Cancer Research Center (M. Kool, unpublished data). ${ }^{30-33}$ The MAS5.0 algorithm of the GCOS program (Affymetrix Inc., Santa Clara, CA) was used for normalization of the expression data. Data were analyzed using the R2: Genomics Analysis and Visualization Platform for analysis and visualization of microarray data (http://R2.amc.nl, last accessed April 15, 2013).

\section{Western Blot Analysis}

Protein was extracted using a Triton X-100-based lysis buffer supplemented with a cOmplete Mini Protease Inhibitor Tablet (Roche, Laval, QC, Canada). Protein $(20 \mu \mathrm{g})$ was loaded into a $10 \%$ denaturing and reducing acrylamide/bisacrylamide (Sigma) gel, and then transferred overnight at $4^{\circ} \mathrm{C}$ onto a polyvinylidene difluoride membrane (BioRad, Mississauga, ON, Canada). Protein bands were visualized using appropriate antibodies and the Enhanced Chemiluminescent (ECL) Prime Western blot detection reagent (GE Healthcare, Mississauga, ON, Canada).

\section{TF and PAI-1 ELISA}

Cells were grown in 6-well (PAI-1) or 10-cm cell culture dishes (TF) to $70 \%$ to $80 \%$ confluence. Cells and EVs were lysed as per the manufacturer's protocol for the Imubind human TF enzyme-linked immunosorbent assay (ELISA; Sekisui Diagnostics) with 5 minutes sonication repeated 3 times before overnight incubation at $4^{\circ} \mathrm{C}$ with constant rotation. For supernatant PAI-1 expression levels, cells were starved overnight and then stimulated with $100 \mathrm{nmol} / \mathrm{L}$ FVIIa for 24 hours before collection of the media, which was centrifuged at $400 \times g$ for 5 minutes to remove cellular debris. Samples were analyzed, according to the manufacturer's instructions, for the Imubind Tissue PAI-1 ELISA (Sekisui Diagnostics).

\section{TF 3'UTR Cloning and Mutagenesis}

Tumor cell-derived RNA was reverse transcribed using the Sensiscript Reverse Transcription kit with random primers 
and RNaseOUT (Life Technologies). Amplification of cDNA was performed using Platinum Taq DNA Polymerase (Life Technologies) and primers (Integrated DNA Technologies, Coralville, IA) specific to the TF $3^{\prime}$ UTR: sense, $5^{\prime}$ GCTAGAGCTCTCATAAAGGAAGCACTGTTGGAG-3'; and antisense, 5'-GCTATCTAGACAGTCATTTACTGTAGTAGAGC-3'. The pmirGLO Dual-Luciferase miRNA Target Expression Vector (Promega, San Luis Obispo, CA) was used to clone the TF $3^{\prime}$ UTR sequence downstream of firefly luciferase (FFL). The plasmid was double digested using XbaI and SacI for 6 hours (New England Biolabs, Ipswich, MA). The PCR product and digested plasmid were purified using QIAquick PCR purification kit (Qiagen, Mississauga, ON, Canada) or ethanol precipitation, respectively. The Quick Ligation kit (New England Biolabs) was used to ligate the insert into the plasmid at $16^{\circ} \mathrm{C}$ overnight. The ligated plasmid was used to transform MAX Efficiency DH5 $\alpha$ Competent Cells (Life Technologies) overnight, and the following day, 20 colonies were picked and tested for the insert by colony PCR, followed by a miniprep (Qiagen) of positive colonies and confirmatory sequencing (Genome Quebec, Montreal, QC, Canada). One plasmid was selected for further assays.

To introduce a three-base mismatch in each of the three potential miR-520g-3p binding sites in the TF $3^{\prime} \mathrm{UTR}$ cloned in the pmirGLO vector, the Transformer SiteDirected Mutagenesis Kit (Clontech, Mountain View, CA) was used according to the manufacturer's instructions. The following are the mutagenic primers: site 1, 5'-CATAAAGGAAGCGAGGTTGGAGCTAC-3'; site 2, 5'-GTTTTGACATCAGCATTAGTAGATTTGAAATGTAACGAATG-3'; and site 3, 5'-CAAAACAATTGGCAAATGGTGTATTAATGTGTTAAGTGC- $3^{\prime}$. The selective primer used has a single-base mutation that deletes the unique XbaI restriction enzyme site in the plasmid, 5'-CAGTAAATGACTGGCTAGAGTCGACC- $3^{\prime}$. Plasmids that were positive for $\mathrm{XbaI}$ deletion were sent for sequencing to determine whether these vectors also had the three base mutations in each of the three potential miR-520g-3p binding sites. All primers were $5^{\prime}$ phosphorylated and purchased from Integrated DNA Technologies.

\section{Dual-Luciferase Assays}

For TF 5 UTR promoter analysis, cells were cotransfected with the -2106 human TF promoter-controlled FFL (Dr. Nigel Mackman, University of North Carolina at Chapel Hill) and pRL-SV40 renilla luciferase plasmids (Promega), the latter for normalization. After 6 hours, the medium was changed and the cells were allowed to recover overnight before 24-hour starvation and 6 hours with or without stimulation with $50 \mathrm{ng} / \mathrm{mL}$ transforming growth factor- $\alpha$. For the TF $3^{\prime}$ UTR dual-luciferase assays, DAOY-pCDH and $-520 \mathrm{~g}$ cells were transfected with the pmirGLO Dual-Luciferase miRNA Target Expression Vector (Promega) with the TF $3^{\prime}$ UTR sequence cloned downstream of FFL. EOMA cells were also cotransfected with control $\mathrm{pCDH}$ or miR-520g expression vectors (System Bioscience, Brockville, ON, Canada). Cells were collected 24 hours after transfection. Luciferase assays were analyzed using the Dual Luciferase Reporter Assay System (Promega).

\section{RNA Preparation and Quantitative Real-Time PCR}

RNA was isolated from cells using the miRNeasy kit (Qiagen), and quantified using Nanodrop. RNA was reverse transcribed using the QuantiTect Reverse Transcription Kit (Qiagen). The cDNA was amplified using the LightCycler480 SYBR Green I Master Mix (Roche). TF and $\beta$-actin primer sets (QuantiTect primer assays) were also purchased from Qiagen. The miRNA was reverse transcribed using the TaqMan miRNA reverse transcription kit and amplified using the TaqMan Universal PCR Master Mix without amperase UNG and TaqMan miRNA primer assays (Life Technologies), including miR-520g-3p (1121), miR-16, and U6 snRNA. Real-time PCR was performed on a LightCycler480 (Roche), and relative mRNA or miRNA levels were quantified from the standard curve for each primer set and normalized to $\beta$-actin for mRNA and miR-16 or U6 snRNA for miRNA using the LightCycler480 Software Release 1.5.0 (Roche).

\section{EV Preparation}

EV-depleted media were prepared from $\alpha$-minimal essential medium supplemented with 20\% FBS and 2\% pen/strep after an overnight ultracentrifugation at $100,000 \times g$. The supernatant was diluted to $10 \%$ FBS and $1 \%$ pen/strep and used for TF experiments. ${ }^{34}$ For miRNA and TF expression in EV fractions, cells were plated in EV-depleted media and incubated for 48 hours. The supernatant was centrifuged twice for 10 minutes at $400 \times g$ to remove cells, which was then followed by an additional centrifugation for 70 minutes at $110,000 \times g$ to isolate the total EV fraction. All centrifugations were performed at $4^{\circ} \mathrm{C}$. EVs were resuspended in Trizol for RNA extraction or lysis buffer for ELISA detection.

\section{Nanoparticle Tracking Analysis}

Indicated cells were grown in 6-well plates in EV-depleted media for 2 days to $70 \%$ to $80 \%$ confluence. The supernatant was centrifuged twice for 10 minutes at $400 \times g$ to remove cells and then analyzed for the EV profile using the Nanosight NS500 instrument (Malvern Instruments Ltd, Worcestershire, UK) the same day. Three measurements of 60 seconds were captured for each sample using the Nanoparticle Tracking Analysis version 2.2 software (Malvern Instruments Ltd), from which an average reading was calculated. Measurement conditions, including the camera shutter, were adjusted for each sample to optimize for the best capture. Analysis conditions were kept constant 
between samples: blur, $9 \times 9$; detection threshold, 8 ; minimum track length, automatic; minimum expected size, $30 \mathrm{~nm}$.

\section{miRNA Inhibitor (Antimir) Transfection}

Cells were seeded in a 6-well plate, grown until $60 \%$ confluent, and transfected with $200 \mathrm{nmol} / \mathrm{L}$ of control or miR-520g-3p (4104416) locked nucleic acid inhibitors (Exiqon, Vedbaek, Denmark) using siRNA transfection reagent (Santa Cruz Biotechnology, Dallas, TX). The medium was changed after 7 hours, and the cells were extracted for protein and RNA 24 hours after transfection.

\section{TF Procoagulant Activity Assay}

Cells were grown in a 24-well plate, and the following day, the medium was removed, and the cells were washed with Tris-buffered saline, $\mathrm{pH} 7.4$, and then incubated in Trisbuffered saline containing $5 \mathrm{nmol} / \mathrm{L}$ FVIIa, $150 \mathrm{nmol} / \mathrm{L}$ FX, and $5 \mathrm{mmol} / \mathrm{L} \mathrm{CaCl}_{2}$ for 30 minutes at $37^{\circ} \mathrm{C}$. An aliquot of each reaction was incubated with chromogenic substrate (Chromogenix, Bedford, MA) in a 96-well plate, according to the manufacturer's instructions, for determination of activated FX (FXa) levels. The reaction was stopped with 50\% acetic acid, and the absorbance was read at $405 \mathrm{~nm}$. The concentration of FXa generated after formation of the TF-FVIIa-FX complex corresponds with the level of TF procoagulant activity. Activity levels were calculated from a standard curve generated from a serial dilution of rabbit brain thromboplastin (TF) and were normalized by total protein.

\section{Xenograft Model}

DAOY stable transfectant cell lines were used to generate s.c. xenografts in immunodeficient yellow fluorescent protein/severe combined immunodeficiency mice by injecting $2 \times 10^{6}$ cells into the flank tissue. Tumor growth was monitored using caliper measurements. At the experimental end point, mice were euthanized and tumor tissues were collected for Western blot analysis of TF levels. All procedures were performed according to an institutionally approved Animal Use Protocol, and were in agreement with guidelines of the Canadian Council of Animal Care.

\section{Statistical Analysis}

Statistical analyses were performed using GraphPad Prism version 6 (GraphPad Software, La Jolla, CA). For twogroup comparisons, data were analyzed using a two-tailed $t$ test (Mann-Whitney test for nonparametric analyses). A one- or two-way analysis of variance was performed as appropriate, and the post hoc Tukey's honestly significant difference test was used to determine the significance of main effects. All data were generally expressed as means \pm SEM, and the level of significance was set as $P \leq 0.05$.

\section{Results}

TF Down-Regulation and Hemostatic Perturbations in ETMRs Harboring the Amplified miRNA Cluster C19MC

The impact of clotting processes in pediatric brain tumors remains relatively unstudied, even though coagulation system effectors are demonstrably expressed in embryonal brain tumors, such as MB. The related signaling and regulatory potentials have been experimentally documented in MB cell lines, where activation of the MET proto-oncogene triggers up-regulation of $\mathrm{TF}$ along with coagulant and angiogenic potentials. ${ }^{1,22,35}$ Hematoxylin and eosin staining of mixed primitive neuroectodermal tumors and C19MCamplified ETMRs indicates the significant presence of blood and blood vessels as well as their close apposition to tumor cells, highlighting the potential for interaction (Supplemental Figure S1). To understand intratumoral clotting events in this setting, we analyzed fibrin deposition in a tissue microarray composed of samples from pediatric embryonal brain tumors, including atypical teratoid/ rhabdoid tumors, primitive neuroectodermal tumors, and ETMRs. Interestingly, martius scarlet blue staining for fibrin revealed differential content of this material between the previously mentioned tumor subtypes with a notable trend toward reduced fibrin levels in ETMR patient samples (Figure 1, A and B). In conjunction with the histological evidence of extravascular blood cells (Supplemental Figure S1), this observation is suggestive of a distinct deregulation of the clotting machinery in ETMR.

We reasoned that one mechanism whereby intratumoral clotting processes could be affected is through aberration in the levels of procoagulant $\mathrm{TF}$, the expression and activity of which are regulated by tumor-specific cellular transformation pathways. ${ }^{1,16,20,21,36}$ Indeed, immunostaining of tumor tissues for $\mathrm{TF}$ protein revealed a marked downregulation of this receptor in C19MC-amplified ETMR compared with tumors without such alteration (Figure 1, C and D). Similarly, we found that TF mRNA is expressed at different levels between embryonal brain tumor types and is significantly lower in ETMRs $(130.9 \pm 22.81)$ compared with atypical teratoid/rhabdoid tumors $(482.5 \pm 106.5)$ (Figure 1E). Together, these data suggest a link between oncogenic C19MC amplification, TF, and the coagulant profile of embryonal brain tumors.

\section{C19MC-Associated miR-520g Triggers TF Down-Regulation in Vivo and in Vitro}

We hypothesized that one or more constituent miRNAs within the amplified C19MC cluster may exert a suppressive effect on TF expression either directly or indirectly. To explore the 
A

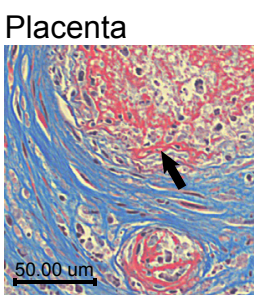

AT/RT

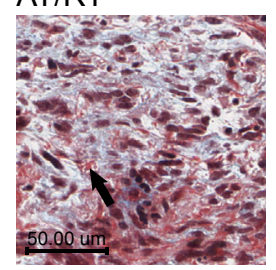

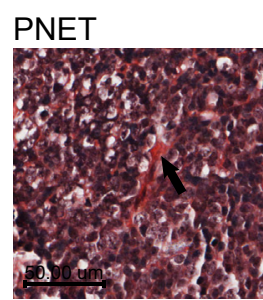

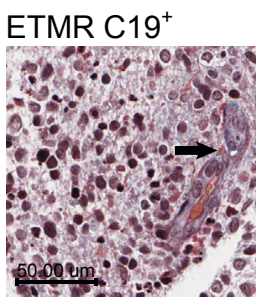

B

Fibrin in Embryonal Brain Tumours

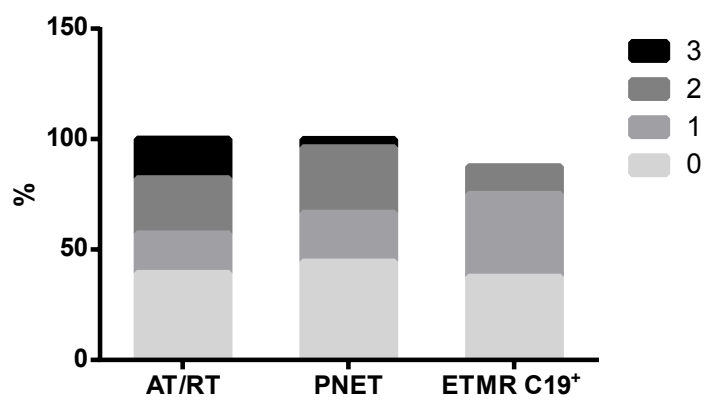

C

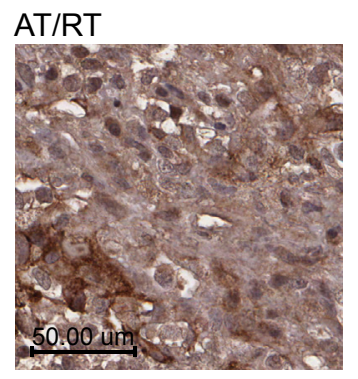

D

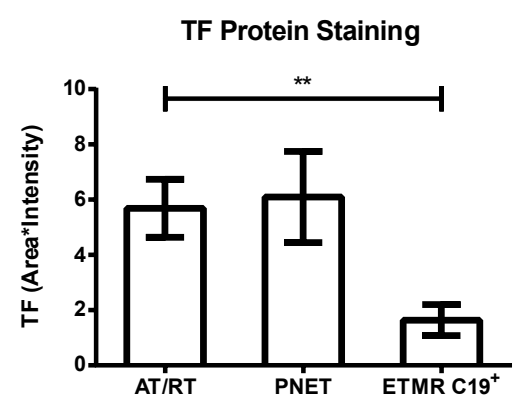

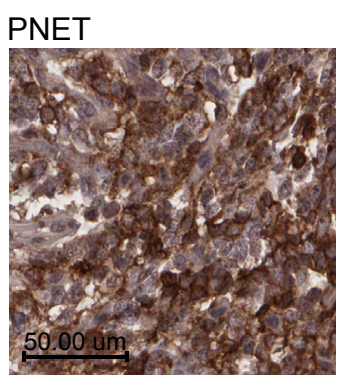

E

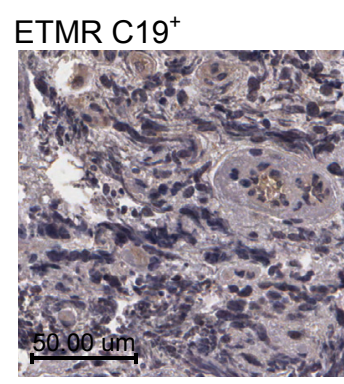

Figure 1 Levels of fibrin exhibit a decreasing trend in embryonal tumors with multilayered rosettes (ETMR) with C19MC amplification $\left({\left.\mathrm{C} 19^{+}\right)}^{+}\right.$ in association with reduced tissue factor (TF) levels. A: The martius scarlet blue (MSB) method stains fibrin in the tissue red (arrows). B: Data represent the percentage of total samples for a specific tumor type that demonstrate a given fibrin intensity score. Patient samples of pediatric embryonal brain tumors were analyzed for TF protein using a $3,3^{\prime}$-diaminobenzidine staining protocol and hematoxylin counterstain (C and D), as well as mRNA expression (E). Values represent means \pm SEM (D and E). Fibrin data: AT/RT, $n=28$; PNET, $n=27$; ETMR C19+, $n=7$. TF protein data: AT/RT, $n=25$; PNET, $n=25$; ETMR C19+, $n=7$. TF mRNA data: normal brain, $n=169 ; \mathrm{AT} / \mathrm{RT}, n=43$; ETMR C19+, $n=16$. ${ }^{*} P<0.05,{ }^{* *} P<0.01$. Original magnification, $\times 40$ (A and C). AT/RT, atypical teratoid/rhabdoid tumor; PNET, primitive neuroectodermal tumor.
TF mRNA expression

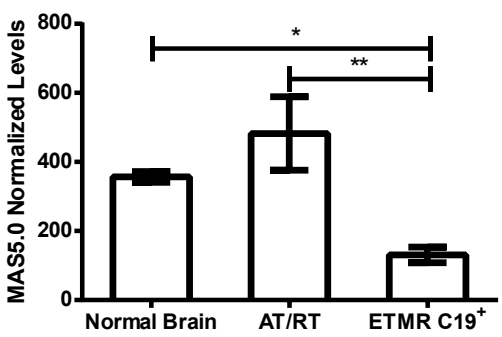

former possibility, we surveyed in silico the top 38 most up-regulated $\mathrm{C} 19 \mathrm{MC}$ miRNAs $^{6,8}$ for the probability of targeting the TF $3^{\prime}$ UTR sequence (Supplemental Table S1). This revealed miR-520g as one of the likely candidates and of special interest because of its previously reported oncogenic activity in ETMR. ${ }^{6}$ Indeed, mining of several miRNA databases (6 of 10), such as DIANAmicroT, miRanda (microRNA.org; http://www.microrna.org/microrna/home. do, last accessed March 7, 2014), miRDB, miRWalk, PICTAR5, and Targetscan, revealed that miR-520g may directly interact with the $3^{\prime} \mathrm{UTR}$ of the TF transcript.

To investigate this possibility more directly, we used pediatric $\mathrm{MB}$ cell lines that exhibit negligible expression of endogenous miR-520g and that were stably transfected with either a control (pCDH) or miR-520g expression vector (Supplemental Figure S2A). ${ }^{6}$ In agreement with our hypothesis, both DAOY-520g and UW228-520g transfectants exhibited reduced levels of TF protein (Figure 2, A-C) and mRNA (Supplemental Figure S2B). This effect was associated with relatively unchanged TF promoter activity, as might be expected in the case of direct miRNA-mediated regulation (Supplemental Figure S2C). TF suppression by miR-520g was not complete, and could be partially restored in the presence of certain growth factors, such as fibroblast growth factor 2, hepatocyte growth factor, and transforming growth factor- $\alpha$, but not platelet-derived growth factor BB (Figure 2C). This is 
A

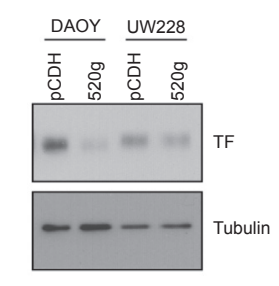

B
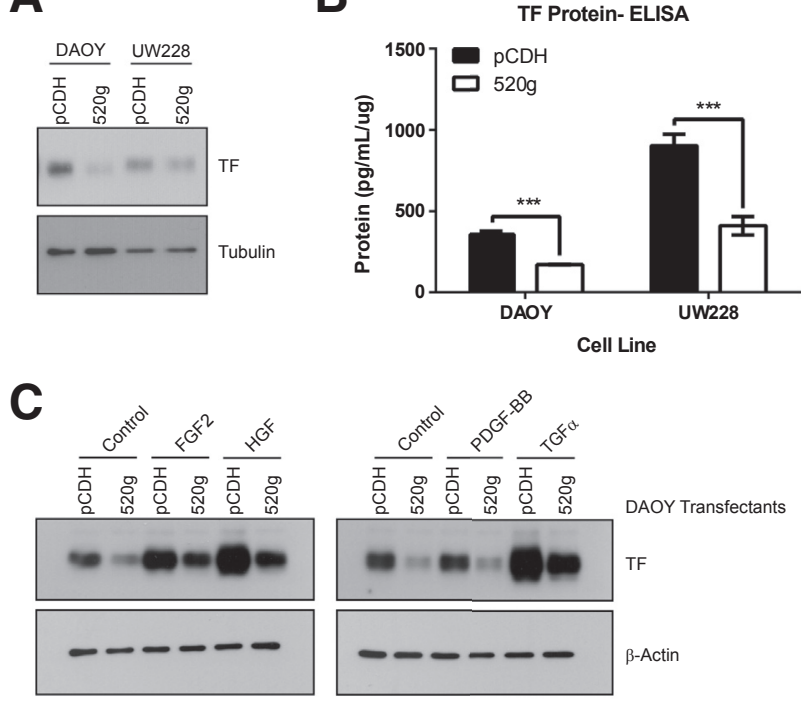

D

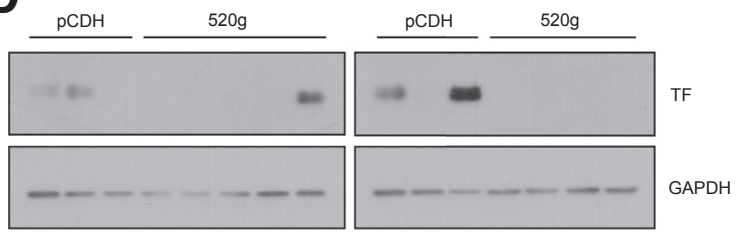

Figure 2 Low levels of tissue factor (TF) protein in embryonal brain tumor cells overexpressing miR-520g. Western blot (A) and enzyme-linked immunosorbent assay (ELISA; $\mathbf{B}$ ) analysis of TF protein in embryonal brain tumor cell lines under basal (A and $\mathbf{B}$ ) and growth factor-stimulated (C) conditions. D: Samples of DAOY-pCDH/-520g tumor xenografts were analyzed for TF protein by Western blot. Values represent means \pm SEM (B). $n=3$ (B); $n=6$ to 9 (D). ${ }^{* * *} P<0.001$. FGF, fibroblast growth factor; HGF, hepatocyte growth factor.

consistent with the ability of the respective oncogenic receptors (MET and EGFR) to transcriptionally up-regulate TF in various cancer settings. ${ }^{1,16,22}$ Indeed, such competing influences may explain our observation that, although DAOY$520 \mathrm{~g}$ tumor xenografts exhibit the expected down-regulation of TF, in most tumors, this expression is variable and to some extent retained, possibly because of paracrine influences in vivo (Figure 2D). This heterogeneity in $\mathrm{TF}$ expression can also be visualized by immunostaining (Supplemental Figure S3).

\section{Impact of miR-520g on Emission of TF as Cargo of EVs}

Oncogenes, miRNA, and TF are known to exit their cellular sources as cargo of EVs, a mechanism that may reduce cellular content and facilitate intercellular transfer of these respective molecules. ${ }^{37-39}$ Notably, emission of TF-containing EVs was implicated as a possible mechanism involved in the procoagulant effects associated with cancer. ${ }^{39}$ In this regard, our group has previously shown that oncogenic lesions, such as RAS or EGFR, can increase the release of EVs and emission of $\mathrm{TF}$ from cancer cells. $^{21,38}$ In keeping with these findings, the expression of
miR-520g (a putative oncomir) resulted in an increased output of exosomal size (50 to $250 \mathrm{~nm}$ ) EVs into the culture medium of DAOY cells, as revealed by nanoparticle tracking analysis (Figure 3A). Moreover, miR-520g was present in the cargo of EVs produced by DAOY $520 \mathrm{~g}$ and the ETMR cell line BT183, but not in control (pCDH) or glioblastoma multiforme (U373vIII) cells, although all cell lines produced EVs containing miR-21 (Figure 3B and Supplemental Figure S4). Finally, EV preparations of miR-520g-overexpressing cells contained lower levels of TF protein relative to control DAOY cells (Figure 3C). Thus,

\section{A Supernatant Extracellular Vesicles}
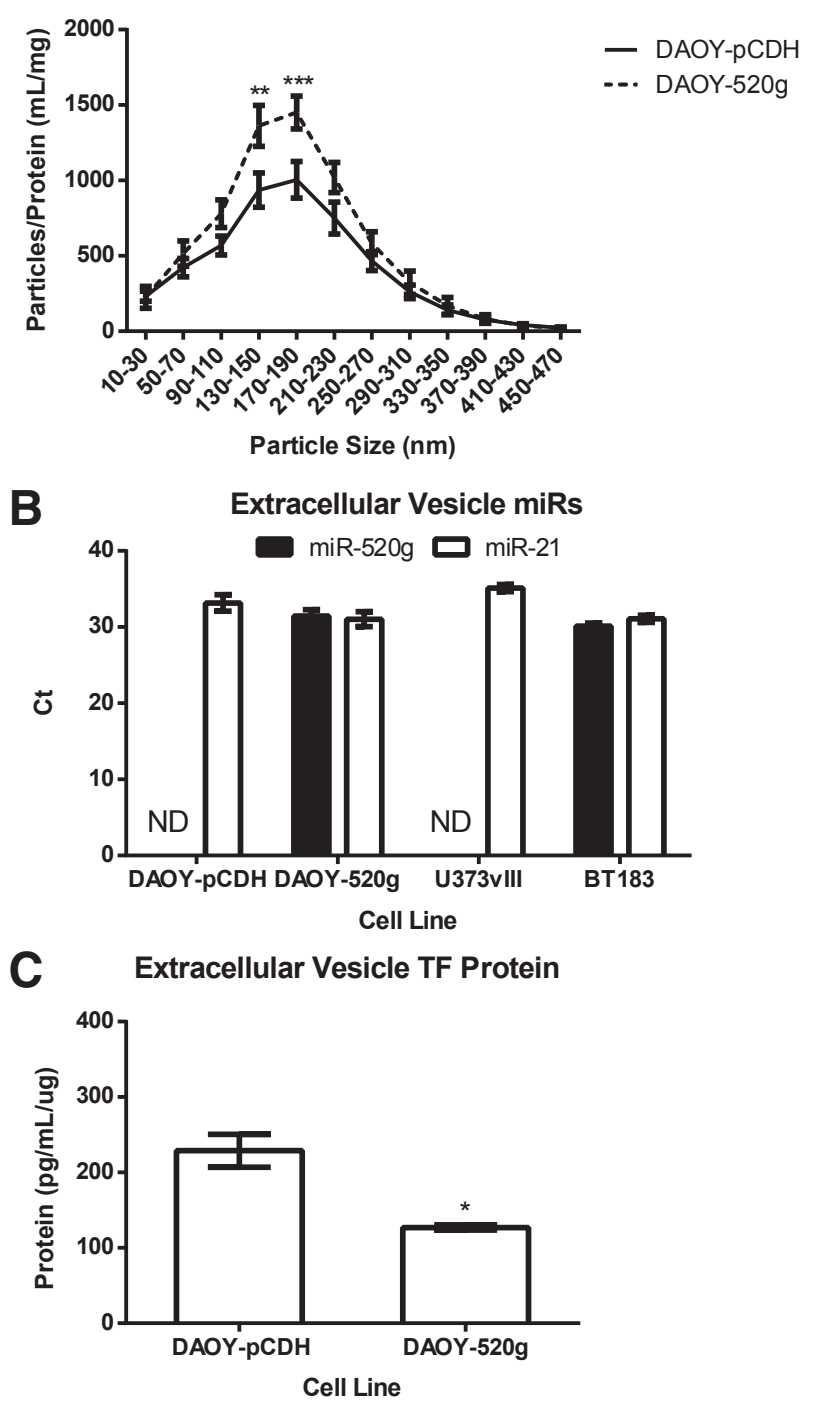

Figure 3 The miR-520g-overexpressing embryonal brain tumor cells release higher numbers of extracellular vesicles (EVs) that contain miR-520g and reduced levels of tissue factor (TF) protein. A: Nanosight analysis of EV sizes and concentrations. B: miR-520g and miR-21 levels of expression in total EV isolates from the cell culture supernatant of DAOY (MB), U373vIII (GBM), and BT183 (ETMT) cell lines. C: TF protein levels in EVs measured using TF enzyme-linked immunosorbent assay. Values represent means \pm SEM (A-C). $n=4$ (A); $n=2$ to 4 (B); $n=3$ (C). ${ }^{*} P<0.05,{ }^{* *} P<0.01$, and ${ }^{* *} P<0.001$. ND, not detectable. 


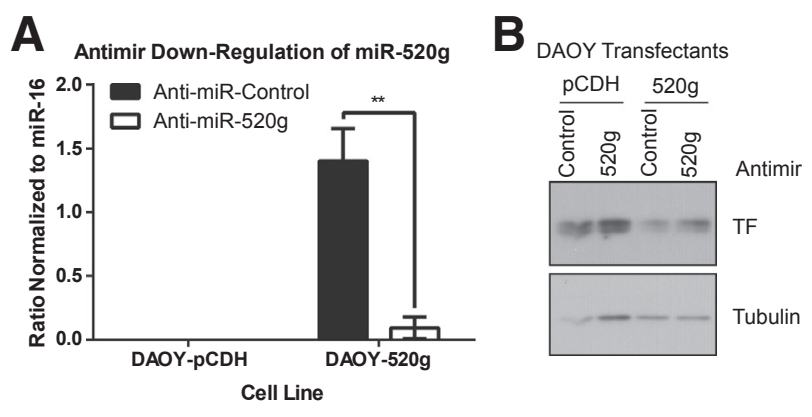

Figure 4 Down-regulation of miR-520g is associated with partial restoration of tissue factor (TF) protein expression. After miR inhibitor transfection of DAOY sublines indicated, we measured levels of miR-520g (A) and TF protein (Western blot; B). Values represent means \pm SEM (A). $n=2(\mathbf{A}) ; n=3$ (B). ${ }^{* *} P<0.01$.

miR-520g stimulates cellular vesiculation while reducing EV-mediated emission of procoagulant TF.

\section{miR-520g Specifically Down-Regulates TF Expression in Cancer Cells}

To further ascertain the causative role of miR-520g in the down-regulation of $\mathrm{TF}$, we reversed this effect using a specific antimir. To accomplish this, both DAOY-pCDH and DAOY $-520 \mathrm{~g}$ cells were transfected with either a control or miR-520g-specific miRNA inhibitor, and tested for miR-520g (Figure 4A) and TF protein (Figure 4B) levels. Indeed, the near complete suppression of miR-520g expression resulted in a notable and specific restoration of TF levels in DAOY-520g cells.

\section{miR-520g Directly Targets the Human TF 3'UTR}

Our in silico sequence analysis positioned $\mathrm{miR}-520 \mathrm{~g}$ as one of the leading candidates for direct TF regulation among the top most highly up-regulated constituents of the C19MC amplicon (Supplemental Table S1). To obtain more direct experimental evidence to this effect, we performed reporter assays using a plasmid expressing FFL upstream of the TF $3^{\prime} \mathrm{UTR}$ regulatory element containing putative miR-520g binding sites. In this setting, a reduction in normalized FFL activity signifies a direct miRNA-mediated effect on the respective transcript. Indeed, we observed that FFL activity was down-regulated in DAOY $-520 \mathrm{~g}$ cells relative to DAOY-pCDH, suggesting the expected effect of miR-520g (Figure 5A).

To eliminate the possible interference of endogenous miR-520g and TF mRNA, we also performed these assays in mouse EOMA cells. These cells contain neither endogenous miR-520g (which is primate specific) nor the human TF sequence present in our $3^{\prime}$ UTR reporter. ${ }^{40}$ EOMA cells were cotransfected with varying concentrations of either the control pCDH or miR-520g expression constructs in the presence of the human TF $3^{\prime}$ UTR FFL reporter, and, as in the case of DAOY, we observed that miR-520g suppressed FFL activity. This was also a dose-dependent effect (Figure 5B), suggesting that the human TF $3^{\prime}$ UTR contains functional miR-520g binding sites.

MiRanda sequence analysis suggests at least three putative miR-520g binding sites within the human TF $3^{\prime} \mathrm{UTR}$. To establish their relative contributions to TF suppression, we introduced three-base mismatches into each of these sites (Figure 5C), and performed FFL reporter assays using DAOY cell lines. As expected, mutation of all sites largely abrogated the effect of miR-520g on FFL activity, and this outcome was closely approximated by a site 2 mutation, but not those of sites 1 and 3 (Figure 5D). These experiments suggest that miR-520g may be targeting primarily the second binding site in the human TF $3^{\prime}$ UTR, which also exhibits the highest binding score for this putative oncomir
A TF 3'UTR Regulation of Luciferase Activity

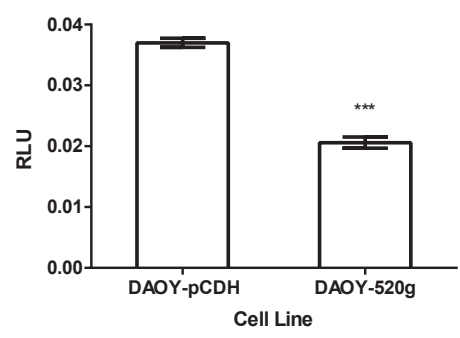

C

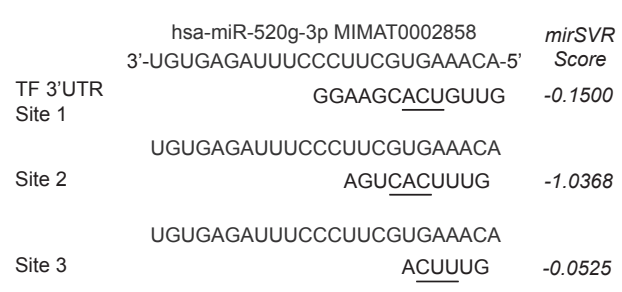

B

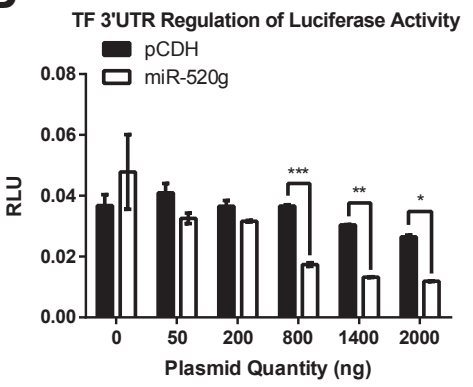

D

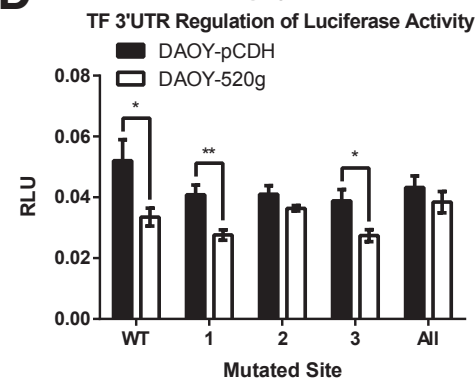

Figure 5 Elevated miR-520g down-regulates tissue factor (TF) expression through direct targeting of sites in the TF $3^{\prime}$ untranslated region (UTR). Firefly luciferase (FFL) activity was measured in DAOY $(\mathbf{A})$ and mouse endothelioma (EOMA; B) cell lines with the TF $3^{\prime} U T R$ sequence cloned downstream of the FFL gene. C: miRBase miR-520g sequence and potential target sites in the TF $3^{\prime}$ UTR, as mapped by microRNA.org ( $h t t p: / / w w w$. microrna.org/microrna/home.do, last accessed March $7,2014)$ with corresponding scores. The underlined sequence corresponds to those nucleotides that were mutated at each site. D: A three-base mismatch was generated at each potential target site alone (1 to 3 ) or in combination (all), and FFL activity was measured in DAOY control and miR-520g stable transfectants. Values represent means $\pm \operatorname{SEM}(\mathbf{A}, \mathbf{B}$, and D). $n=3$ (A and $\mathbf{B}) ; n=5$ to 6 (D). ${ }^{*} P<0.05,{ }^{* *} P<0.01$, and ${ }^{* * *} P<0.001$. RLU, relative luciferase unit; WT, wild type. 


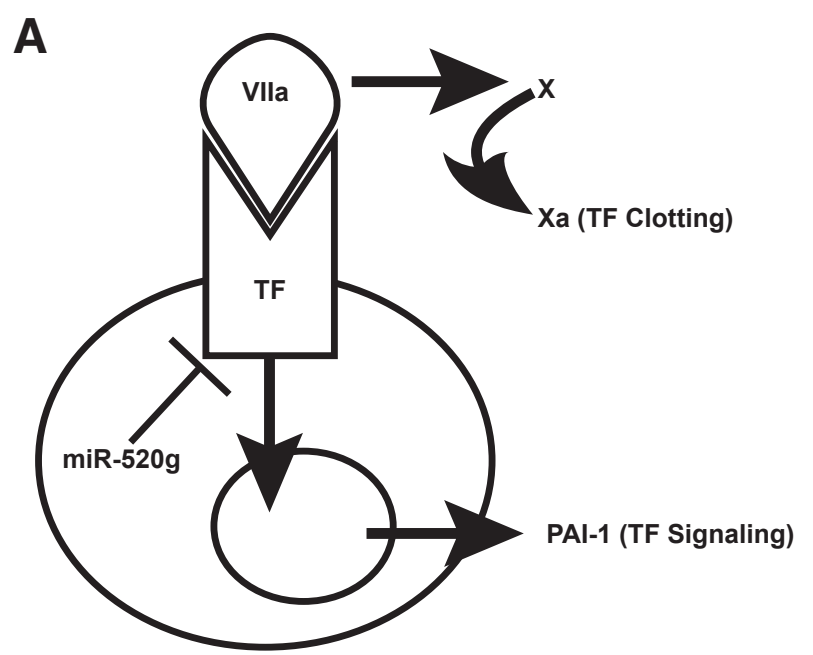

B

TF Procoagulant Activity

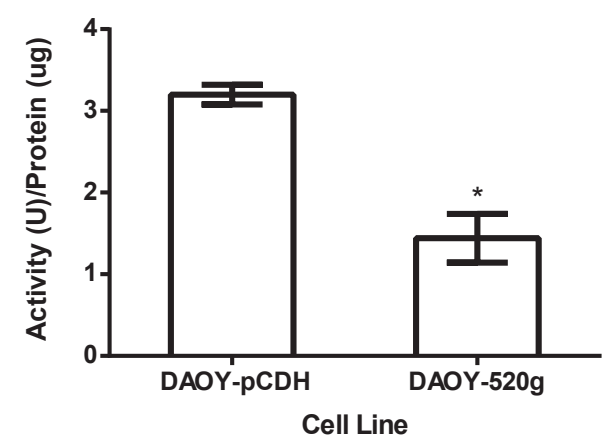

C

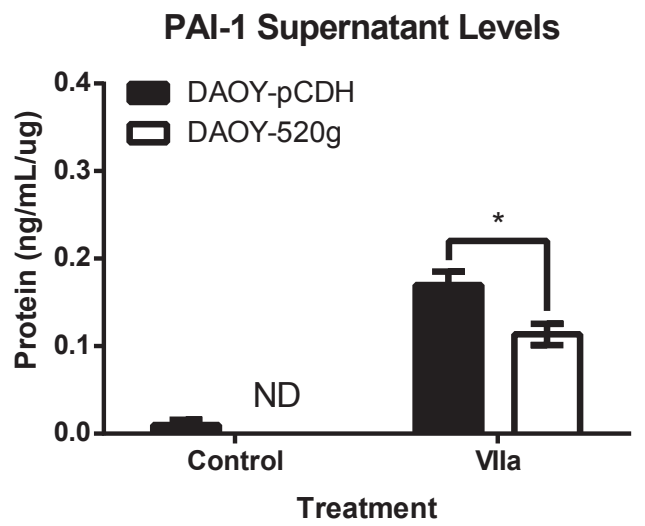

Figure 6 Low tissue factor (TF) levels in miR-520g-overexpressing embryonal tumor cells are associated with reduced procoagulant potential. A: TF function was assessed by measuring its extracellular activity [factor $\mathrm{Xa}$ (FXa) generation] and its capacity in regulating gene expression [plasminogen activator inhibitor 1 (PAI-1)]. B: Activation of the extracellular coagulation cascade was measured by determining levels of FXa produced in the cell culture supernatant. C: PAI-1 produced and released from cells was measured after factor VIIa stimulation. Values represent means \pm SEM (B and C). $n=2$ (B); $n=3$ (C). ${ }^{*} P<0.05$. ND, not detectable.

(Figure 5C). Collectively, these results suggest that at least one component of the C19MC amplicon, miR-520g, specifically down-regulates TF, and this occurs as a result of direct targeting of the $3^{\prime} \mathrm{UTR}$ of the TF transcript.
Suppression of TF Procoagulant and Signaling Functions in miR-520g-0verexpressing Cancer Cells

The crucial biological role of TF is related to its ability to trigger the coagulation cascade and to change cellular gene expression patterns on contact with blood-borne coagulation FVIIa, the key TF ligand. These effects can be measured by the ability of TF-expressing cells to activate exogenous coagulation factor X (FX to FXa) and to increase levels of PAI-1, a serpine known to be regulated by the TF signaling pathway. ${ }^{41}$ These are biologically convergent effects because FXa is essential for the formation of fibrin clots, and PAI-1 inhibits the activation of plasminogen into plasmin, thereby impeding fibrin degradation ${ }^{42}$ (Figure 6A). We surmised that both of these activities would be reduced in cells expressing miR-520g. Indeed, we found that DAOY-520g cells exhibit reduced TF procoagulant activity, as measured by FXa generation compared with the control DAOY-pCDH cell line (Figure 6B). Furthermore, FVIIa stimulation of PAI-1 release was significantly reduced in miR-520g-overexpressing cells (Figure 6C). These experiments suggest that miR-520g not only affects the expression of TF but also reduces associated downstream biologically relevant procoagulant and signaling effects. This is consistent with the reduced fibrin staining pattern observed in ETMR tumors, and may be indicative of the potential role of the C19MC cluster in tumor-vascular interactions and formation of a hemorrhagic microenvironment.

\section{Endogenous miR-520g Can Be Elevated in Stem Cell-Like Culture Conditions in Concert with Reduced TF}

We have earlier proposed that the coagulation system may constitute an important element of the cancer stem cell niche, ${ }^{43}$ and recent data suggest enrichment for such cells in soft fibrin cultures. ${ }^{44}$ This is a relevant consideration in the context of ETMR because the expression of miRNAs contained in the C19MC cluster (including miR-520g) is restricted to primitive early neuronal progenitor cells, a phenotype that may be recapitulated in ETMR, which exhibits amplification of this locus. ${ }^{6,8}$ Therefore, we reasoned that miR-520g could be reexpressed in less primitive cancer cells after removal of the methylation block or by growth in stem cell-like (sphere) cultures. In both pediatric (DAOY) and adult (U373vIII) brain tumor cells, miR-520g dramatically increases after treatment with a demethylating agent (5-aza-2'-deoxycytidine) (Figure 7A).

To assess whether miR-520g expression can be rescued under stem-like growth conditions, DAOY cells were cultured as spheres in stem cell medium containing growth factors. Remarkably, this treatment led to a robust upregulation of endogenous miR-520g (Figure 7B) and a concomitant decrease in TF protein expression (Figure 7C). Although stem cell medium contains growth factors that are 


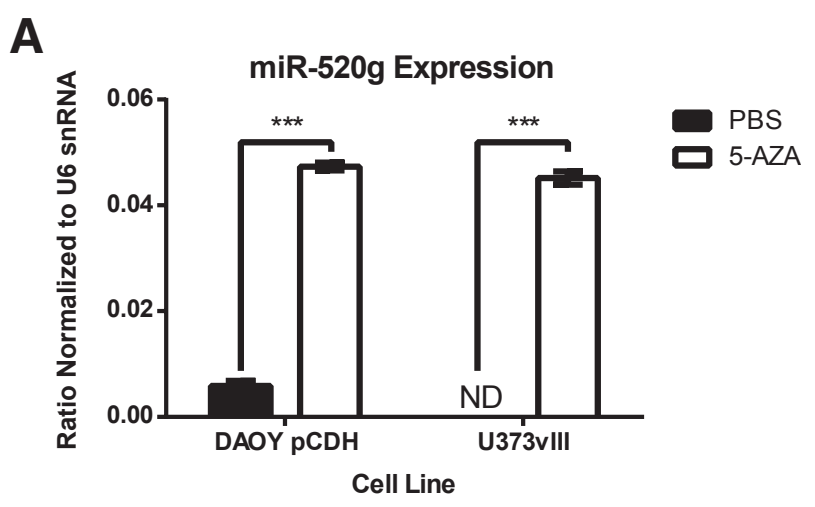

B
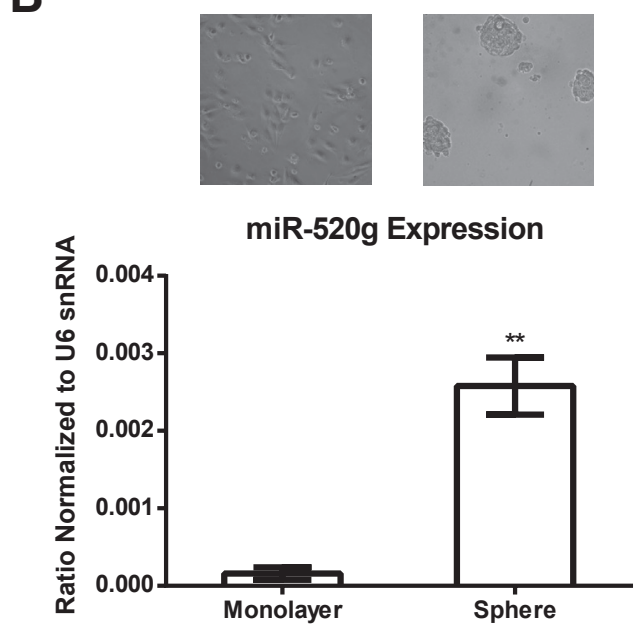

C

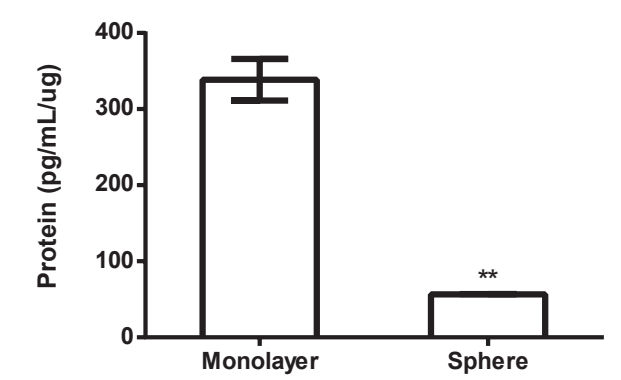

Figure 7 Endogenous miR-520g is up-regulated in embryonal brain tumor cells grown as spheres in concert with down-regulated tissue factor (TF) protein expression. A: DAOY and U373vIII cells were treated with 5-aza-2'-deoxycytidine (5-AZA), a demethylation agent, and levels of miR-520g were measured. DAOY cells were grown as spheres in stem cell media and analyzed for miR-520g (B) and TF protein expression (C). Light microscope images were captured. Values represent means \pm SEM $(\mathbf{A}-\mathbf{C})$. $n=2$ (A and C); $n=3$ (B). ${ }^{* *} P<0.01,{ }^{* * *} P<0.001$. ND, not detectable; PBS, phosphate-buffered saline.

able to up-regulate TF expression (Figure 2C), the opposite was the case in the presence of an increase in endogenous miR-520g levels. These observations highlight the prospective functional link between the C19MC-associated endogenous miR-520g and TF expression. This may suggest that in ETMR the enrichment for primitive cancer cells and C19MC amplification may favor a pericellular milieu with low coagulant activity within the stem cell niche (Supplemental Figure S5).

\section{Discussion}

The central objective of our present study was to explore whether oncogenic miRNAs expressed in pediatric embryonal brain tumor cells can affect the vascular microenvironment. Therefore, we focused our efforts on ETMR, a paradigm of embryonal brain malignancy driven by oncogenic amplification of the miRNA cluster $\mathrm{C} 19 \mathrm{MC},{ }^{5,6}$ and on $\mathrm{TF}$, the crucial regulator of coagulation and angiogenesis. In this regard, we report several new findings. First, we found that tumors positive for C19MC amplification demonstrate an altered vascular microenvironment, as exemplified by reduced fibrin content and lower levels of TF. Second, we established that at least one miRNA within the C19MC cluster (Supplemental Table S1), miR-520g, can directly and specifically target TF for down-regulation, which is associated with reduced procoagulant and signaling potential of cancer cells in vitro. Third, we observed that cellular miR-520g is incorporated into EVs and stimulates vesiculation but not EV-mediated emission of TF. Fourth, we provide initial evidence for the link between miR-520g reexpression and TF down-regulation in stem cell-like growth conditions, a notion that may apply to ETMR, but also to other embryonal brain tumor types in which miR-520g/TF interactions could be restricted to a subset of cancer (stem-like) cells.

Our results highlight the genetic and cellular mechanisms that may influence the diversity of vascular microenvironments among human brain tumors. Thus, the effects of the putative oncomir miR-520g and the vascular patterns observed in ETMR suggest that in pediatric brain tumors enriched for primitive stem cells, low coagulant activity may be either favorable or tolerable for the progressing disease. In contrast, our earlier study on MB, another pediatric embryonal brain tumor, suggests that in certain subtypes of the disease, the TF pathway may be up-regulated, and coagulant effectors may drive the expression of angiogenesis-related genes, especially in conjunction with proto-oncogenic growth factor receptors, such as MET. ${ }^{1}$ Furthermore, in high-grade adult primary brain tumors, the coagulation pathway is frequently activated, leading to both local $^{45}$ and systemic ${ }^{24}$ coagulopathy. In this setting, our earlier studies suggested a role for molecular tumor subtypes in determining the profile of coagulation-related gene expression, ${ }^{23}$ the functional involvement of $\mathrm{TF}$ in tumorigenesis, ${ }^{14}$ and the role of oncogenic EGFR in the up-regulation of TF. ${ }^{16}$

Our study may also offer a voice in discussion as to the biological role of the coagulation system in cancer, irrespective of clinically overt coagulopathy. Indeed, children diagnosed with high-grade brain tumors rarely develop systemic thromboembolic complications, in contrast to their adult counterparts. ${ }^{24,25,46}$ This is despite the preponderance 
of vascular anomalies within the tumor mass, such as ischemic necrosis, hemorrhage, endothelial hyperplasia, and abnormal blood vessel structures. ${ }^{3,4,47}$ These features are indicative of silent clotting system perturbations, which are likely (implicitly) exacerbated by the common use of invasive (surgical) therapeutic strategies in the treatment of brain tumors. Thus, inevitable hemostatic system responses could elicit some of their well-documented biological effects, such as inflammation, angiogenesis, immunomodulation, and tissue repair processes, regardless of clinically manifest thrombosis. The biological importance and therapeutic implications of these connections remain poorly studied. More important, coagulation events may have different biological consequences in specific subtypes of brain tumors, ranging from various forms of stimulation to inhibition of the malignant process.

In this regard, we documented herein and elsewhere ${ }^{1,21,23}$ that coagulation-related events are influenced by oncogenic lesions, the diversity of which may dictate similarly diverse mechanisms of hemostatic and angiogenic deregulation. Without molecular stratification, this diversity may be perceived as unspecific. For example, the unique C19MC genomic amplification may have a particular role in the formation of the vascular microenvironment relevant to the biology of ETMR, an example of a primitive brain tumor enriched in stem cell characteristics, ${ }^{7,48}$ but other cancers may require/trigger completely different vascular responses associated with thrombosis. ${ }^{49}$

Childhood cancers are often regarded as being driven by developmental abnormalities, ${ }^{50}$ a notion highlighting their relatively simpler mutational make-up, frequent epigenetic deregulation, and involvement of cellular differentiation pathways, including control of the stem cell compartment. This is exemplified by ETMR, which arises in young patients and within a developmentally immature cellular milieu. ${ }^{2}$ ETMRs demonstrate a stem-like molecular profile, including the expression of LIN28A, and the TTYHI promoter-C19MC fusion and consequent miRNA-related deregulation of RBL2 and DNMT3B genes involved in the control of early developmental programs. ${ }^{7,8,48} \mathrm{~A}$ miRNA profiling study highlighted that human embryonic stem cells contain high levels of C19MC miRNAs compared with more differentiated cell types, where they are silenced by methylation. ${ }^{51-54}$ It has also been documented that constituents of the $\mathrm{C} 19 \mathrm{MC}$ cluster, such as miR-517c and $\mathrm{miR}-520 \mathrm{~g}$, can increase the expression of stem cell markers in cells of neuronal origin. ${ }^{6}$ Collectively, these studies support the notion that the C19MC cluster, including miR-520g, is linked to an early neuronal stem cell phenotype often associated with access to, and properties of, the vascular stem cell niche. ${ }^{55}$

Stem cells in various settings were reported to up-regulate $\mathrm{TF}^{43}$ or protein $\mathrm{C}$ receptor ${ }^{56,57}$; respond to the stimulation of thrombin receptors ${ }^{58}$; express $\mathrm{TF}$ pathway inhibitor, an inhibitor of TF function ${ }^{59}$; or favor growth in soft fibrin gels. ${ }^{44}$ In other contexts, TF levels were shown to be significantly lower in (cancer) stem cell populations compared with more differentiated cells, ${ }^{56,60}$ suggesting the existence of several distinct biological processes. Low TF protein in embryonic stem cells compared with more differentiated cells is necessary to prevent failure of implantation, and miR-20b is, at least in part, involved in this down-regulation. ${ }^{60}$ TF-regulating miRNAs also include members of the MYC oncogene-activated miR-17-92 cluster, which, among other functional aspects, plays an important role in regulating angiogenesis, invasion, and stemness. ${ }^{12,60-64}$ Notably, miR-17-92 is a direct transcriptional target of Nanog, one of the core pluripotency transcription factors that maintains self-renewal in embryonic stem cells. ${ }^{64,65}$ These findings bear some analogy to our results with ETMR, which is enriched in stem cell characteristics and harbors high levels of C19MC miRNAs associated with low TF and an undifferentiated cell state. ${ }^{7,48}$ The role of epigenetic pathways in the control of the stem cell phenotype ${ }^{8}$ and the link between DNA methylation and the levels of miR-520g, ${ }^{52-54}$ is also consistent with our observations. This may separate malignancies driven by epigenetic alterations from those harboring oncogenic mutations in key cellular signaling nodes (eg, EGFR) and often associated with high levels of TF. ${ }^{23}$

We observed that endogenous miR-520g up-regulation and TF down-regulation coincide under stem cell culture conditions. Such cultures are performed in the presence of cell-cell contact and growth factors (EGF) able to stimulate TF expression. ${ }^{14}$ Although our results are consistent with the ability of miR-520g to counter the effects of growth factors and serum (added to cellular monolayers) (Figure 2, $\mathrm{A}-\mathrm{C}$ ), further studies are needed to understand the complexities of TF regulation among stem cell-like cancer cell populations of different origin.

Both miRNAs and TF have been detected in the cargo of circulating EVs in various cancer settings. ${ }^{66,67}$ In this regard, our study suggests that EV-associated C19MC miRNAs, especially miR-520g, could reflect the molecular makeup of ETMR, and could be considered as a plausible plasma biomarker in this disease. ${ }^{48,68}$ Although EV-mediated transfer of molecular cargo has been implicated as a mechanism of intercellular communication, ${ }^{38}$ the levels of miR-520g in EVs produced by DAOY transfectants were, in our hands, relatively low and thereby unlikely to exert such a robust effect, as predicted by the recent study. ${ }^{69}$

Several studies have explored different roles of C19MC miRNAs in cancer and implicated them as either tumor suppressing or oncogenic. $6,8,52,53,70-77$ The targets of miR-520g thus far include matrix metalloproteinase 2 in endometriosis, ${ }^{75}$ as well as the more recently reported $\mathrm{p} 21$ and SMAD7 in colorectal and hepatocellular carcinoma cells, ${ }^{78,79}$ respectively; however, TF is presented in our study for the first time.

Although the link between oncomirs and vascular effectors is fascinating, several questions remain unanswered. Not all ETMR samples are positive for miR-520g. ${ }^{8}$ It would 
be of interest to explore whether these infrequent miR$520 \mathrm{~g}-$ negative tumors constitute a distinct subset with different vascular properties, or whether other miRNAs are involved in TF regulation in this setting. The functional role of TF in ETMR biology is also of interest in view of targeting or diagnostic opportunities. It is of considerable interest whether C19MC, including miR-520g, affects other relevant vascular (coagulant, inflammatory, or angiogenic) tumor characteristics, either alone or in the context of a wider cellular phenotype. These could be important considerations in view of the growing interest in targeting the vascular stroma in currently incurable brain tumors, such as ETMR, and our observations may contribute to this line of investigation by suggesting more personalized approaches.

\section{Acknowledgments}

We thank our colleagues for helpful suggestions, the Goodman Cancer Research Center Histology Core (McGill University, Montreal, QC, Canada) for their services, and our families for their continuous encouragement.

\section{Supplemental Data}

Supplemental material for this article can be found at http://dx.doi.org/10.1016/j.ajpath.2015.10.020.

\section{References}

1. D’Asti E, Kool M, Pfister SM, Rak J: Coagulation and angiogenic gene expression profiles are defined by molecular subgroups of medulloblastoma: evidence for growth factor-thrombin cross-talk. J Thromb Haemost 2014, 12:1838-1849

2. Korshunov A, Sturm D, Ryzhova M, Hovestadt V, Gessi M, Jones DT, Remke M, Northcott P, Perry A, Picard D, Rosenblum M, Antonelli M, Aronica E, Schuller U, Hasselblatt M, Woehrer A, Zheludkova O, Kumirova E, Puget S, Taylor MD, Giangaspero F, Peter Collins V, von Deimling A, Lichter P, Huang A, Pietsch T, Pfister SM, Kool M: Embryonal tumor with abundant neuropil and true rosettes (ETANTR), ependymoblastoma, and medulloepithelioma share molecular similarity and comprise a single clinicopathological entity. Acta Neuropathol 2014, 128:279-289

3. Goldbrunner RH, Pietsch T, Vince GH, Bernstein JJ, Wagner S, Hageman H, Selby DM, Krauss J, Soerensen N, Tonn JC: Different vascular patterns of medulloblastoma and supratentorial primitive neuroectodermal tumors. Int J Dev Neurosci 1999, 17:593-599

4. Buccoliero AM, Castiglione F, Rossi Degl'Innocenti D, Franchi A, Paglierani M, Sanzo M, Cetica V, Giunti L, Sardi I, Genitori L, Taddei GL: Embryonal tumor with abundant neuropil and true rosettes: morphological, immunohistochemical, ultrastructural and molecular study of a case showing features of medulloepithelioma and areas of mesenchymal and epithelial differentiation. Neuropathology 2010, 30:84-91

5. Pfister S, Remke M, Castoldi M, Bai AH, Muckenthaler MU, Kulozik A, von Deimling A, Pscherer A, Lichter P, Korshunov A: Novel genomic amplification targeting the microRNA cluster at 19q13.42 in a pediatric embryonal tumor with abundant neuropil and true rosettes. Acta Neuropathol 2009, 117:457-464

6. Li M, Lee KF, Lu Y, Clarke I, Shih D, Eberhart C, Collins VP, Van Meter T, Picard D, Zhou L, Boutros PC, Modena P, Liang ML,
Scherer SW, Bouffet E, Rutka JT, Pomeroy SL, Lau CC, Taylor MD, Gajjar A, Dirks PB, Hawkins CE, Huang A: Frequent amplification of a chr19q13.41 microRNA polycistron in aggressive primitive neuroectodermal brain tumors. Cancer Cell 2009, 16:533-546

7. Picard D, Miller S, Hawkins CE, Bouffet E, Rogers HA, Chan TS, Kim SK, Ra YS, Fangusaro J, Korshunov A, Toledano H, Nakamura H, Hayden JT, Chan J, Lafay-Cousin L, Hu P, Fan X, Muraszko KM, Pomeroy SL, Lau CC, Ng HK, Jones C, Van Meter T, Clifford SC, Eberhart C, Gajjar A, Pfister SM, Grundy RG, Huang A: Markers of survival and metastatic potential in childhood CNS primitive neuro-ectodermal brain tumours: an integrative genomic analysis. Lancet Oncol 2012, 13:838-848

8. Kleinman CL, Gerges N, Papillon-Cavanagh S, Sin-Chan P, Pramatarova A, Quang DA, et al: Fusion of TTYH1 with the C19MC microRNA cluster drives expression of a brain-specific DNMT3B isoform in the embryonal brain tumor ETMR. Nat Genet 2014, 46:39-44

9. Ha M, Kim VN: Regulation of microRNA biogenesis. Nat Rev Mol Cell Biol 2014, 15:509-524

10. Di Leva G, Garofalo M, Croce CM: MicroRNAs in cancer. Annu Rev Pathol 2014, 9:287-314

11. Landskroner-Eiger S, Moneke I, Sessa WC: miRNAs as modulators of angiogenesis. Cold Spring Harb Perspect Med 2013, 3:a006643

12. Dews M, Homayouni A, Yu D, Murphy D, Sevignani C, Wentzel E, Furth EE, Lee WM, Enders GH, Mendell JT, Thomas-Tikhonenko A: Augmentation of tumor angiogenesis by a Myc-activated microRNA cluster. Nat Genet 2006, 38:1060-1065

13. Trousseau A: Plegmasia alba dolens. Lectures on clinical medicine. Delivered at the Hotel-Dieu, Paris, 1865, 5:281-332

14. Magnus N, Garnier D, Meehan B, McGraw S, Lee TH, Caron M, Bourque G, Milsom C, Jabado N, Trasler J, Pawlinski R, Mackman N, Rak J: Tissue factor expression provokes escape from tumor dormancy and leads to genomic alterations. Proc Natl Acad Sci U S A 2014, 111:3544-3549

15. Adams RL, Bird RJ: Review article: coagulation cascade and therapeutics update: relevance to nephrology, part 1: overview of coagulation, thrombophilias and history of anticoagulants. Nephrology (Carlton) 2009, 14:462-470

16. Milsom CC, Yu JL, Mackman N, Micallef J, Anderson GM, Guha A, Rak JW: Tissue factor regulation by epidermal growth factor receptor and epithelial-to-mesenchymal transitions: effect on tumor initiation and angiogenesis. Cancer Res 2008, 68:10068-10076

17. Mackman N: Triggers, targets and treatments for thrombosis. Nature 2008, 451:914-918

18. Albrektsen T, Sorensen BB, Hjorto GM, Fleckner J, Rao LV, Petersen LC: Transcriptional program induced by factor VIIa-tissue factor, PAR1 and PAR2 in MDA-MB-231 cells. J Thromb Haemost 2007, 5:1588-1597

19. Ruf W, Disse J, Carneiro-Lobo TC, Yokota N, Schaffner F: Tissue factor and cell signalling in cancer progression and thrombosis. J Thromb Haemost 2011, 9 Suppl 1:306-315

20. Rong Y, Post DE, Pieper RO, Durden DL, Van Meir EG, Brat DJ: PTEN and hypoxia regulate tissue factor expression and plasma coagulation by glioblastoma. Cancer Res 2005, 65:1406-1413

21. Yu JL, May L, Lhotak V, Shahrzad S, Shirasawa S, Weitz JI, Coomber BL, Mackman N, Rak JW: Oncogenic events regulate tissue factor expression in colorectal cancer cells: implications for tumor progression and angiogenesis. Blood 2005, 105:1734-1741

22. Provencal M, Labbe D, Veitch R, Boivin D, Rivard GE, Sartelet H, Robitaille Y, Gingras D, Beliveau R: c-Met activation in medulloblastoma induces tissue factor expression and activity: effects on cell migration. Carcinogenesis 2009, 30:1089-1096

23. Magnus N, Gerges N, Jabado N, Rak J: Coagulation-related gene expression profile in glioblastoma is defined by molecular disease subtype. J Thromb Haemost 2013, 11:1197-1200

24. Stein PD, Beemath A, Meyers FA, Skaf E, Sanchez J, Olson RE: Incidence of venous thromboembolism in patients hospitalized with cancer. Am J Med 2006, 119:60-68 
25. Athale U, Siciliano S, Thabane L, Pai N, Cox S, Lathia A, Khan A, Armstrong A, Chan AK: Epidemiology and clinical risk factors predisposing to thromboembolism in children with cancer. Pediatr Blood Cancer 2008, 51:792-797

26. Obeso J, Weber J, Auerbach R: A hemangioendothelioma-derived cell line: its use as a model for the study of endothelial cell biology. Lab Invest 1990, 63:259-269

27. Spence T, Perotti C, Sin-Chan P, Picard D, Wu W, Singh A, Anderson C, Blough MD, Cairncross JG, Lafay-Cousin L, Strother D, Hawkins C, Narendran A, Huang A, Chan JA: A novel C19MC amplified cell line links Lin28/let-7 to mTOR signaling in embryonal tumor with multilayered rosettes. Neuro Oncol 2014, 16:62-71

28. Wang X, Venugopal C, Manoranjan B, McFarlane N, O'Farrell E, Nolte S, Gunnarsson T, Hollenberg R, Kwiecien J, Northcott P, Taylor MD, Hawkins C, Singh SK: Sonic hedgehog regulates Bmil in human medulloblastoma brain tumor-initiating cells. Oncogene 2012, 31:187-199

29. Ferguson AT, Evron E, Umbricht CB, Pandita TK, Chan TA, Hermeking H, Marks JR, Lambers AR, Futreal PA, Stampfer MR, Sukumar S: High frequency of hypermethylation at the 14-3-3 $\sigma$ locus leads to gene silencing in breast cancer. Proc Natl Acad Sci U S A 2000, 97:6049-6054

30. Kool M, Jones DT, Jager N, Northcott PA, Pugh TJ, Hovestadt V, et al: Genome sequencing of SHH medulloblastoma predicts genotype-related response to smoothened inhibition. Cancer Cell 2014, 25:393-405

31. Kool M, Koster J, Bunt J, Hasselt NE, Lakeman A, van Sluis P, Troost D, Meeteren NS, Caron HN, Cloos J, Mrsic A, Ylstra B, Grajkowska W, Hartmann W, Pietsch T, Ellison D, Clifford SC, Versteeg R: Integrated genomics identifies five medulloblastoma subtypes with distinct genetic profiles, pathway signatures and clinicopathological features. PLoS One 2008, 3:e3088

32. Fattet $\mathrm{S}$, Haberler $\mathrm{C}$, Legoix $\mathrm{P}$, Varlet $\mathrm{P}$, Lellouch-Tubiana A, Lair S, Manie E, Raquin MA, Bours D, Carpentier S, Barillot E, Grill J, Doz F, Puget S, Janoueix-Lerosey I, Delattre O: Beta-catenin status in paediatric medulloblastomas: correlation of immunohistochemical expression with mutational status, genetic profiles, and clinical characteristics. J Pathol 2009, 218:86-94

33. Robinson G, Parker M, Kranenburg TA, Lu C, Chen X, Ding L, et al: Novel mutations target distinct subgroups of medulloblastoma. Nature 2012, 488:43-48

34. Théry C, Amigorena S, Raposo G, Clayton A: Isolation and characterization of exosomes from cell culture supernatants and biological fluids. Curr Protoc Cell Biol 2006, Chapter 3:Unit 3.22

35. Provencal M, Berger-Thibault N, Labbe D, Veitch R, Boivin D, Rivard GE, Gingras D, Beliveau R: Tissue factor mediates the HGF/Met-induced anti-apoptotic pathway in DAOY medulloblastoma cells. J Neuro Oncol 2010, 97:365-372

36. Magnus N, Garnier D, Rak J: Oncogenic epidermal growth factor receptor up-regulates multiple elements of the tissue factor signaling pathway in human glioma cells. Blood 2010, 116: $815-818$

37. Valadi H, Ekstrom K, Bossios A, Sjostrand M, Lee JJ, Lotvall JO: Exosome-mediated transfer of mRNAs and microRNAs is a novel mechanism of genetic exchange between cells. Nat Cell Biol 2007, 9: 654-659

38. Al-Nedawi K, Meehan B, Micallef J, Lhotak V, May L, Guha A, Rak J: Intercellular transfer of the oncogenic receptor EGFRvIII by microvesicles derived from tumour cells. Nat Cell Biol 2008, 10: 619-624

39. Garnier D, Magnus N, Lee TH, Bentley V, Meehan B, Milsom C, Montermini L, Kislinger T, Rak J: Cancer cells induced to express mesenchymal phenotype release exosome-like extracellular vesicles carrying tissue factor. J Biol Chem 2012, 287:43565-43572
40. Tsai KW, Kao HW, Chen HC, Chen SJ, Lin WC: Epigenetic control of the expression of a primate-specific microRNA cluster in human cancer cells. Epigenetics 2009, 4:587-592

41. McEachron TA, Pawlinski R, Richards KL, Church FC, Mackman N: Protease-activated receptors mediate crosstalk between coagulation and fibrinolysis. Blood 2010, 116:5037-5044

42. Hagood JS, Olman MA, Godoy JA, Rivera KE, Fuller GM: Regulation of type I plasminogen activator inhibitor by fibrin degradation products in rat lung fibroblasts. Blood 1996, 87:3749-3757

43. Milsom C, Magnus N, Meehan B, Al-Nedawi K, Garnier D, Rak J: Tissue factor and cancer stem cells: is there a linkage? Arterioscler Thromb Vasc Biol 2009, 29:2005-2014

44. Liu J, Tan Y, Zhang H, Zhang Y, Xu P, Chen J, Poh YC, Tang K, Wang N, Huang B: Soft fibrin gels promote selection and growth of tumorigenic cells. Nat Mater 2012, 11:734-741

45. Tehrani M, Friedman TM, Olson JJ, Brat DJ: Intravascular thrombosis in central nervous system malignancies: a potential role in astrocytoma progression to glioblastoma. Brain Pathol 2008, 18: $164-171$

46. Tabori U, Beni-Adani L, Dvir R, Burstein Y, Feldman Z, Pessach I, Rechavi G, Constantini S, Toren A: Risk of venous thromboembolism in pediatric patients with brain tumors. Pediatr Blood Cancer 2004, 43:633-636

47. Maire JP, Guerin J, Rivel J, San Galli F, Bernard C, Dautheribes M, Caudry M: [Medulloblastoma in children: prognostic incidence of vascular hyperplasia, coagulation necrosis and postoperative clinical state on survival] French. Neurochirurgie 1992, 38:80-88

48. Korshunov A, Ryzhova M, Jones DT, Northcott PA, van Sluis P, Volckmann R, Koster J, Versteeg R, Cowdrey C, Perry A, Picard D, Rosenblum M, Giangaspero F, Aronica E, Schuller U, Hasselblatt M, Collins VP, von Deimling A, Lichter P, Huang A, Pfister SM, Kool M: LIN28A immunoreactivity is a potent diagnostic marker of embryonal tumor with multilayered rosettes (ETMR). Acta Neuropathol 2012, 124:875-881

49. Northcott PA, Korshunov A, Witt H, Hielscher T, Eberhart CG, Mack S, Bouffet E, Clifford SC, Hawkins CE, French P, Rutka JT, Pfister S, Taylor MD: Medulloblastoma comprises four distinct molecular variants. J Clin Oncol 2011, 29:1408-1414

50. Scotting PJ, Walker DA, Perilongo G: Childhood solid tumours: a developmental disorder. Nat Rev Cancer 2005, 5:481-488

51. Ren J, Jin P, Wang E, Marincola FM, Stroncek DF: MicroRNA and gene expression patterns in the differentiation of human embryonic stem cells. J Transl Med 2009, 7:20

52. Yoshitomi T, Kawakami K, Enokida H, Chiyomaru T, Kagara I, Tatarano S, Yoshino H, Arimura H, Nishiyama K, Seki N, Nakagawa M: Restoration of miR-517a expression induces cell apoptosis in bladder cancer cell lines. Oncol Rep 2011, 25:1661-1668

53. Zhang S, Shan C, Kong G, Du Y, Ye L, Zhang X: MicroRNA-520e suppresses growth of hepatoma cells by targeting the NF-kappaBinducing kinase (NIK). Oncogene 2012, 31:3607-3620

54. Liu RF, Xu X, Huang J, Fei QL, Chen F, Li YD, Han ZG: Downregulation of miR-517a and miR-517c promotes proliferation of hepatocellular carcinoma cells via targeting Pyk2. Cancer Lett 2013, 329:164-173

55. Calabrese C, Poppleton H, Kocak M, Hogg TL, Fuller C, Hamner B, Oh EY, Gaber MW, Finklestein D, Allen M, Frank A, Bayazitov IT, Zakharenko SS, Gajjar A, Davidoff A, Gilbertson RJ: A perivascular niche for brain tumor stem cells. Cancer Cell 2007, 11:69-82

56. Schaffner F, Yokota N, Carneiro-Lobo T, Kitano M, Schaffer M, Anderson GM, Mueller BM, Esmon CT, Ruf W: Endothelial protein $\mathrm{C}$ receptor function in murine and human breast cancer development. PLoS One 2013, 8:e61071

57. Wang D, Cai C, Dong X, Yu QC, Zhang XO, Yang L, Zeng YA: Identification of multipotent mammary stem cells by protein $\mathrm{C}$ receptor expression. Nature 2015, 517:81-84 
58. Wautier F, Wislet-Gendebien S, Chanas G, Rogister B, Leprince P: Regulation of nestin expression by thrombin and cell density in cultures of bone mesenchymal stem cells and radial glial cells. BMC Neurosci 2007, 8:104

59. Eppert K, Takenaka K, Lechman ER, Waldron L, Nilsson B, van Galen P, Metzeler KH, Poeppl A, Ling V, Beyene J, Canty AJ, Danska JS, Bohlander SK, Buske C, Minden MD, Golub TR, Jurisica I, Ebert BL, Dick JE: Stem cell gene expression programs influence clinical outcome in human leukemia. Nat Med 2011, 17: 1086-1093

60. Yu Y-H, Wu D-S, Huang F-F, Zhang Z, Liu L-X, Zhang J, Zhan H-E, Peng M-Y, Zeng H, Chen F-P: MicroRNA-20b and ERK1/2 pathway independently regulate the expression of tissue factor in hematopoietic and trophoblastic differentiation of human embryonic stem cells. Stem Cell Res Ther 2013, 4:121

61. Zhang X, Yu H, Lou JR, Zheng J, Zhu H, Popescu NI, Lupu F, Lind SE, Ding WQ: MicroRNA-19 (miR-19) regulates tissue factor expression in breast cancer cells. J Biol Chem 2011, 286:1429-1435

62. Yu G, Li H, Wang X, Wu T, Zhu J, Huang S, Wan Y, Tang J: MicroRNA-19a targets tissue factor to inhibit colon cancer cells migration and invasion. Mol Cell Biochem 2013, 380:239-247

63. Teruel R, Perez-Sanchez C, Corral J, Herranz MT, Perez-Andreu V, Saiz E, Garcia-Barbera N, Martinez-Martinez I, Roldan V, Vicente V, Lopez-Pedrera C, Martinez C: Identification of miRNAs as potential modulators of tissue factor expression in patients with systemic lupus erythematosus and antiphospholipid syndrome. J Thromb Haemost 2011, 9:1985-1992

64. Garg N, Po A, Miele E, Campese AF, Begalli F, Silvano M, Infante P, Capalbo C, De Smaele E, Canettieri G, Di Marcotullio L, Screpanti I, Ferretti E, Gulino A: microRNA-17-92 cluster is a direct Nanog target and controls neural stem cell through Trp53inp1. EMBO J 2013, 32:2819-2832

65. Boyer LA, Lee TI, Cole MF, Johnstone SE, Levine SS, Zucker JP, Guenther MG, Kumar RM, Murray HL, Jenner RG, Gifford DK, Melton DA, Jaenisch R, Young RA: Core transcriptional regulatory circuitry in human embryonic stem cells. Cell 2005, 122:947-956

66. Chen X, Ba Y, Ma L, Cai X, Yin Y, Wang K, Guo J, Zhang Y, Chen J, Guo X, Li Q, Li X, Wang W, Zhang Y, Wang J, Jiang X, Xiang Y, Xu C, Zheng P, Zhang J, Li R, Zhang H, Shang X, Gong T, Ning G, Wang J, Zen K, Zhang J, Zhang CY: Characterization of microRNAs in serum: a novel class of biomarkers for diagnosis of cancer and other diseases. Cell Res 2008, 18: 997-1006

67. Geddings JE, Mackman N: Tumor-derived tissue factor-positive microparticles and venous thrombosis in cancer patients. Blood 2013, 122:1873-1880

68. Korshunov A, Remke M, Gessi M, Ryzhova M, Hielscher T, Witt H, Tobias V, Buccoliero AM, Sardi I, Gardiman MP, Bonnin J, Scheithauer B, Kulozik AE, Witt O, Mork S, von Deimling A,
Wiestler OD, Giangaspero F, Rosenblum M, Pietsch T, Lichter P, Pfister SM: Focal genomic amplification at 19q13.42 comprises a powerful diagnostic marker for embryonal tumors with ependymoblastic rosettes. Acta Neuropathol 2010, 120:253-260

69. Chevillet JR, Kang Q, Ruf IK, Briggs HA, Vojtech LN, Hughes SM, Cheng HH, Arroyo JD, Meredith EK, Gallichotte EN, PogosovaAgadjanyan EL, Morrissey C, Stirewalt DL, Hladik F, Yu EY, Higano CS, Tewari M: Quantitative and stoichiometric analysis of the microRNA content of exosomes. Proc Natl Acad Sci U S A 2014, 111:14888-14893

70. Cui W, Zhang Y, Hu N, Shan C, Zhang S, Zhang W, Zhang X, Ye L: miRNA-520b and miR-520e sensitize breast cancer cells to complement attack via directly targeting 3'UTR of CD46. Cancer Biol Ther 2010, 10:232-241

71. Huang Q, Gumireddy K, Schrier M, le Sage C, Nagel R, Nair S, Egan DA, Li A, Huang G, Klein-Szanto AJ, Gimotty PA, Katsaros D, Coukos G, Zhang L, Pure E, Agami R: The microRNAs miR-373 and miR-520c promote tumour invasion and metastasis. Nat Cell Biol 2008, 10:202-210

72. Keklikoglou I, Koerner C, Schmidt C, Zhang JD, Heckmann D, Shavinskaya A, Allgayer H, Guckel B, Fehm T, Schneeweiss A, Sahin O, Wiemann S, Tschulena U: MicroRNA-520/373 family functions as a tumor suppressor in estrogen receptor negative breast cancer by targeting NF-kappaB and TGF-beta signaling pathways. Oncogene 2012, 31:4150-4163

73. Liu P, Wilson MJ: miR-520c and miR-373 upregulate MMP9 expression by targeting mTOR and SIRT1, and activate the Ras/Raf/MEK/Erk signaling pathway and NF-kappaB factor in human fibrosarcoma cells. J Cell Physiol 2012, 227:867-876

74. Su JL, Chen PB, Chen YH, Chen SC, Chang YW, Jan YH, Cheng X, Hsiao M, Hung MC: Downregulation of microRNA miR-520h by E1A contributes to anticancer activity. Cancer Res 2010, 70: 5096-5108

75. Tsai EM, Wang YS, Lin CS, Lin WY, Hsi E, Wu MT, Juo SH: A microRNA-520 mirSNP at the MMP2 gene influences susceptibility to endometriosis in Chinese women. J Hum Genet 2013, 58:202-209

76. Wang F, Xue X, Wei J, An Y, Yao J, Cai H, Wu J, Dai C, Qian Z, Xu Z, Miao Y: Hsa-miR-520h downregulates ABCG2 in pancreatic cancer cells to inhibit migration, invasion, and side populations. Br J Cancer 2010, 103:567-574

77. Zhang W, Kong G, Zhang J, Wang T, Ye L, Zhang X: MicroRNA$520 \mathrm{~b}$ inhibits growth of hepatoma cells by targeting MEKK2 and cyclin D1. PLoS One 2012, 7:e31450

78. Zhang Y, Geng L, Talmon G, Wang J: MicroRNA-520g confers drug resistance by regulating p21 expression in colorectal cancer. J Biol Chem 2015, 290:6215-6225

79. Kan H, Guo W, Huang Y, Liu D: MicroRNA-520g induces epithelial-mesenchymal transition and promotes metastasis of hepatocellular carcinoma by targeting SMAD7. FEBS Lett 2015, 589:102-109 